\title{
Histopathology and Ultrastructural Findings of Fatal COVID-19 Infections in Kurdistan Province, Iran: A Case Series
}

\author{
Bahram Nikkhoo \\ Kurdistan University of Medical Sciences \\ Karim Nasseri \\ Kurdistan University of Medical Sciences \\ Mohammad Aziz Rasouli \\ Kurdistan University of Medical Sciences \\ Bahar Moasses-Ghafari ( $\nabla$ baharmoassesghafari@gmail.com ) \\ Kurdistan University of Medical Sciences
}

\section{Research}

Keywords: Histopathology, Ultrastructural, Covid-19, Iran

Posted Date: October 6th, 2021

DOI: https://doi.org/10.21203/rs.3.rs-951413/v1

License: (c) (1) This work is licensed under a Creative Commons Attribution 4.0 International License. Read Full License 


\section{Abstract}

Background: Coronaviruses, including severe acute respiratory syndrome coronavirus (SARS-CoV) and is the cause of an ongoing pandemic, with increasing deaths worldwide. Here in we present the results of the histopathological study of the main organs of 25 patients who died due to confirmed COVID-19.

Methods: In this case series, patients base on needle necropsy of multiple organs of dead patients with a positive antemortem SARS-CoV-2 (COVID-19) real time PCR. Needle necropsy of corpses of 25 patients enrolling the study were performed until 3 hours after death in the negative-pressure isolation morgue who hospitalized at Kurdistan University of medical sciences Tohid and Kowsar hospitals with proved COVID-19 infection and were died due to severe disease manifestations.

Results: The mean age of the participants in this study was $74.68 \pm 9.41$ (52-91) years old. The participants included 19 men (76\%) and 6 women (24\%). In myocardial necropsy, twelve patients were reported to be lymphocytic myocarditis, three of them were reported to have pericarditis as well, and in one case focal visual fibrosis was reported. Histopathological examinations of liver revealed that among twentytwo samples, five cases had acute hepatitis that four of them were mild in type. Steatohepatitis was reported in six cases and two of them were macrovesicular in type. Macrovesicular Steatosis was reported along with steatohepatitis and stage 4 fibrosis through trichrome staining. Muscles necropsy revealed viral myositis for three patients.

Conclusions: Our study shows extra-pulmonary multi organ involvement through COVID-19 disease. $77 \%$ of patients representing acute or chronic hepatitis and $48 \%$ of them revealed lymphocytic myocarditis accompanied with pericarditis in $12 \%$ of cases and $12 \%$ of patient's show myositis. It looks diffuse inflammatory disease which attacks to some organs like myocardium, liver and muscles. Broad extra pulmonary pathology and laboratory findings are occurred that all suggestive of multi organ involvement directly or through systemic viremia and immune system response.

\section{Background}

The high mortality rate of coronavirus (COVID-19) made it at the forefront of the scientific and health news during the last 17 months (1). So, immediate management of COVID-19 in terms of recognizing its epidemiological and pathological dimensions is essential due to its impact on various aspects of human lives worldwide (2). Though, multiple histopathological studies have been conducted in the field of post mortem autopsy but it still seems that the number of these studies is limited compared to the extent of disease and more assessments are demanded (3-7).

Needle necropsy is one of the method to evaluation of pathogenesis in main organs of dead patients due to Covid-19 with high level of infectivity by considering the principles of personal protection. Needle necropsy can be a useful way to determine underlying pathology in sudden death of communicable disease such COVID-19 and to save lives $(5,6)$. Although in early steps of the epidemic autopsies were more focused on pulmonary parenchyma, however gradually by identifying the involvement of various organ involvement in Covid-19 viremia, histopathological studies also shifted to multi organ sampling $(1,5)$. Here in we present the results of the histopathological study of the main organs of 25 patients who died due to confirmed COVID-19.

\section{Methods}

\section{Patient's selection and necropsy procedures}

This case series study designed base on needle necropsy of multiple organs of dead patients with a positive antemortem SARS-CoV-2 real time Polymerase chain reaction (PCR) from April 2020 to August 2020. The patients were included in the study who hospitalized at Kurdistan University of medical sciences Tohid and Kowsar hospitals with proved COVID-19 infection and were died due to severe disease manifestations. Both hospitals used the CDC-designed 2019 CoV real-time RT-PCR assay for virus detection. Needle necropsy of corpses of 25 patients enrolling the study were performed until 3 hours after death in the negative-pressure isolation morgue of the both hospitals. Full observance of health protocols and personal safety protection in accordance with the guidelines of the World Health Organization (WHO) were considered. Five formalin-filled containers were submitted per necropsy sampling of multi organs consisting heart, liver, muscles, breasts and scrotum. Next they transmitted to pathology laboratory in short time by observing all principles of the relevant standards. The license of the University Ethics Committee was obtained before the study began (IR.MUK.REC.1399.024).

\section{Histologic examination}


Necropsy materials of multi organs were put in containers filled by $10 \%$ neutral buffered formalin and labeled by patient's name, hospital and admission ward and then for standard processing, paraffin embedding, microtome sectioning and finally hematoxylin and eosin staining. For liver and heart samples trichrome and iron stains were done additionally.

\section{Personal Safety Considerations}

Complete precautions were taken during performing the necropsy in accordance with WHO guidelines to prevent infection during sampling including wearing a special gowns, gloves, eyeglasses, face mask and all necessary shielding.

\section{Data Analysis}

Descriptive statistical methods were used to present the collected data. All statistical analyses were performed using Stata16.0 software (StataCorp, College Station, TX).

\section{Results}

\section{Patient characteristics}

The mean age of the participants in this study was 74.68 \pm 9.41 (52-91) years old. The participants included 19 men (76\%) and 6 women (24\%). Regarding underlying diseases, 18 patients were recognized. One of the patients had one kidney and seven of them had no comorbidities. The mean time of hospitalization was 7 days for patients, and the mean time of hospitalization in Intensive Care Unit (ICU) was 4.4 days and hospitalization in wards was 3.7 days. A patient was hospitalized for 54 days, and he was deleted from the average calculation (Table 1).

Fever, fatigue and pulmonary distress were the most common primary symptoms. Intubation was conducted for 19 patients (76\%) during the time of hospitalization. Other patients were intubated during cardiopulmonary resuscitation (CPR). Most of the intubation cases were performed in the first 24 hours of admission. Two patients were intubated and expired six hours after being admitted to the emergency ward. All patients were treated using venous anticoagulants or subcutaneous injection except for four ones (Table 1).

Patients' medical records were retrospectively reviewed. The requested laboratory tests showed that lactic acid dehydrogenase (LDH) had been measured in 17 cases, which were reported for five patients over 1000, including cases 3, 10, 15, 17 and 2 with LDH levels of 1649, $1274,1037,1011$, and 7158, respectively. The highest level of LDH (7158) belonged to patient number 2, which had eighty-four year old. LDH was 500 to1000 in eight cases (patients No. 6, 7, 8, 9, 13, 14, 16, and 20), and was normal (<500) in four cases. Serum creatinine level was reported in the range of 1-3 for all patients except for three cases. An eighty-six-year-old woman with CKD and HTN (Patient No. 14) and fifty-two-year-old woman (Patient No. 8) with Hypertension (HTN) in their history were reported to have Cr=7. A sixty-sevenyear-old man (Patient No. 12) with chronic active hepatitis was reported to have $\mathrm{Cr}=5$. Blood urea nitrogen (BUN) was reported in the range from 74 to 218 for sixteen patients. Creatine phosphokinase (CPK) was reported in the range from 61 to 4984 for twelve cases. The highest level of CPK belonged to cases number 5, 6, and 10. The reported CPK levels were reported 4984, 2261, and 1032, respectively. The CPK level was reported 829 and 779 for cases number 17 and 12. Erythrocyte sedimentation rate (ESR) was in the range from 16 to >100 for eleven cases. The highest level belonged to patient number 19 (>100). D-dimer was checked for eight patients. It was reported 2188 for patient number 3 who was 80 years old male with previous medical history of cereberovascular accident (CVA) and 200 for three cases (cases number 2, 15, 20) that were 84-year- old male, 91-year- old male and 71-year-old female with single kidney respectively. The checked D-dimer was reported 115 for patient number 8 . Patient number 2, had the highest LDH level (7158). CRP and ESR were reported 68 and 16. The patient had $\mathrm{Hb}=13$ and $\mathrm{Hct}=60.1$ at admission, and the before mentioned factors were reported 20 and 58.4 before death. At the time of admission, Plt was 203 and White blood cells (WBC) was reported 14.3 and at the time of death they were registered as Plt=185 and $W B C=14$. Hemoglobin level was checked at the time of admission for nineteen patients. $\mathrm{Hb}<6$ was reported in four cases (number 8 , 14,17 , and 23 ). For patient number $20, \mathrm{Hb}=8$ was reported at the time of admission. The range of $\mathrm{Hb}$ was $10-15 \mathrm{for}$ the other ten patients (Table 3).

Hemoglobin (HB) level for patient's number 13, 9, 6, and 2 were 17.10, 17.70, 20, and 21.6 respectively. The lowest hemoglobin level checked before death belonged to the patient number $25(\mathrm{Hb}=2.63)$. Plt checked for patients ranged from 31 (in Patient No. 8$)$ up to 324 (for Patient No. 19). White blood cells of the patients ranged from 5-15.50. For case number $6, \mathrm{Hb}=21.6, \mathrm{Hct}=56.8, \mathrm{Plt}=89$, and $\mathrm{WBC}=5$ were reported at the time of admission. Hb was decreased to 16.4 with $\mathrm{Hct}=48$ and Plt=15 before expiry. Ferritin was measured for nine patients and the results ranged from 8.5 to 2375. The ferritin level was reported above 2000 in three cases including case number 14 (2375), number 9 (2250), and number 3 (2310). It was reported 1650 for case number 10 and 500 for cases Patients No. 2, 8,25 . Calcium was checked for nine patients. The results ranged from $7.50 \mathrm{mg} / \mathrm{dl}$ in patient number 6 to $9.10 \mathrm{mg} / \mathrm{dl}$ in patient's number 2 and 7 (Table 1 )

Page $3 / 11$ 
Magnesium (Mg) was checked in twelve patients. The results ranged 1.7 (for Patient No. 3) and 3 (for Patients No. 2 and 20 ). Serum glutamic oxaloacetic transaminase (SGOT) and serum glutamic pyruvic transaminase (SGPT) were measured for fifteen patients. SGOT ranged 18 (case number 20) to 180 (case number 12). SGPT ranged 10 (case number 18) to 3170 (case number 12). ALKP was checked in thirteen patients. The results ranged 119 (case number 9) to 373 (case number 11) (Table 2).

Eighteen patients had clinically significant comorbidities, the most common being hypertension, CVA, and diabetes disease (Table 3)

\section{Histopathological analysis}

In myocardial necropsy, twelve patients were reported to be lymphocytic myocarditis, three of them were reported to have pericarditis as well (Patients No. 13, 20, 21), and in one case focal visual fibrosis was reported (Patient No. 12) (Figure 1, Figure 2). Histopathological examinations of liver revealed that among twenty-two samples, five cases had acute hepatitis that four of them were mild in type. Steatohepatitis was reported in six cases and two of them were macrovesicular in type (Patients No. 21, 23) (Figure 3). Chronic active hepatitis was reported in four cases. Liver necropsy revealed that there was one case of cirrhosis (Patient No. 13) (Figure 4). Also there was a case of incomplete cirrhosis (Patient No. 11). Macrovesicular Steatosis was reported along with steatohepatitis and stage 4 fibrosis through trichrome staining for patient number 21. Mild periportal fibrosis (stage 1) was observed for patient number 23. Muscles necropsy revealed viral myositis for three patients(Patients No. 11,12,18). Testicular necropsy revealed one case of sertoli-cell only syndrome (germinal cell aplasia) and other testicular samples were unremarkable (Table 4).

\section{Discussion}

A vast range of pathologic findings have been reported about expired COVID-19 patients $(8,9)$. Several histopathologic evidences of severe extrapulmonary involvement leading to death in SARS-Cov-2 patients were investigated (1).

Endothelial injury risk increases along with micro thrombosis risk in COVID-19 patient $(1,10)$. Microvascular injuries in coronavirus infection were reported in initial reports proving endotheliitis as well as endothelial cells containing Corona viruses like particles in COVID19 patients (11). However, regarding endothelial injuries, investigating endothelial cells containing corona virus is being done (12). A study, conducted using an electron microscope or immunohistochemistry, revealed the presence of corona viruses like particles in renal endothelial cells. However, similar findings were not reported in investigating endothelial cells of other organs. Moreover, histologic evidences for endotheliitis were not reported. In some studies, conducted using complete autopsy, evidences supporting micro thrombosis were not reported (1).

Cardiac injuries are prevalent in covid-19 patients although some studies did not reveal evidences supporting it (1). In a clinical study, 33\% of ICU patients in Kirkland had cardiomyopathy with unclear reasons. After expiration, RNA of the virus was found in cardiac tissues of a patient. However, histopathologic evidences supporting myocarditis were not found (13).

In a study, 3 out of 14 patients had increased troponin; myocarditis histopathologic evidences were found for only one patient (1). In the present study, viral lymphocytic myocarditis histopathologic evidences were found in 12 patients, which is more than similar studies. It is important to mention that pericarditis in 3 patients and focal fibrosis in a patient were reported.

In the study 3 patients out of 14 had troponin increase and histopathologic evidences for myocarditis were found for only one patient (1). Viral RNA was extracted from PCR. However, immunohistochemistry and electron microscope results were negative. Regarding the fact that the patient had viremia, the low RNA extracted from cardiac tissues might be caused by viremia and the viruses in the bloodstream rather than direct injuries of the cardiac tissues.

The extension of extrapulmonary involvement in SARS-Cov-2 patients suffering from the non-severe type of COVID-19 is still unclear. Since SARS-Cov-2 was reported in stool and urine sample tests of non-severe type COVID-19 patients, there are evidences supporting presence of infection in extrapulmonary tissues $(14,15)$. These reports highlight concerns about high risk groups like patients suffering from chronic renal diseases, renal transplant and inflammatory bowel diseases patients. If such patients are exposed to higher risks of SARS-Cov-2 complications, accurate monitoring of these patients seems necessary.

Although extrapulmonary involvement in sub-clinical and mild type COVID-19 patients is lower, extrapulmonary active infection in patients without pulmonary infection has remained unclear.

One of the limitations of the present study is that sampling was not performed under the guide of ultrasound. Therefore, necropsy failed in some patients and sampling from liver tissues of three patients was not done correctly. So, those cases were excluded from the study.

Page $4 / 11$ 
Inflammatory myocarditis in 48\% of patients, pericarditis in 3 patients (Patients No. 13, 20, 21), as well as inflammation in liver and muscles revealed the extent of inflammatory involvement in COVID-19 patients, which sometimes emerge with focal fibrosis.

Hepatitis has been observed as a super imposed disease to the underlying diseases in patients with chronic underlying liver diseases like cirrhosis. In the present study, 6 patients were suffering from hepatic steatosis.

Macrovesicular type was reported in 3 cases and stage 4 fibrosis was reported in one case. Five patients had acute hepatitis. This means that 11 patients (44\% of the cases) experienced acute hepatitis. Four patients had chronic hepatitis. Active chronic hepatitis indicating stage 1, 2 fibrosis. Therefore, $60 \%$ of the patients had acute or chronic hepatitis according to histology findings. COVID-19 induced cirrhosis was reported in one patient (Patient No. 13) that was recognized with mild type acute hepatitis, negative trichrome staining and negative iron).

Overall, the main findings are $24 \%$ hepatic steatosis and $44 \%$ acute hepatitis. Regarding the number of patients with active chronic hepatitis, $60 \%$ of the patients had experienced different levels of hepatitis.

Fat droplets in hepatocytes along with vesicular steatosis were demonstrated in photomicrograph of small case series studies.

In Tian S et al. study, core needle biopsy of four patients' liver demonstrated that liver histopathologic changes were not exclusive, and the results might be associated to previous problems or perimortem injuries (13).

A study demonstrated moderate acute hepatitis along with acute cell rejection in patients receiving liver allograft $(16,17)$. Concerning the vast spectrum of the observed histopathology of liver in several studies, a significant question must be noticed. The question is whether the liver is directly affected by virus invasion or whether the damages are resulted from cytokine storm, or both.

The angiotensin converting enzyme receptors (ACE 2), commonly found on cholangiocytes in liver and rarely on hepatocytes, have been recognized as the main mode of entering cells. However, the number of the receptors increases on hepatocytes in physiologic stressful conditions (18). They are found on endothelial cells of portal liver coroners, either (11).

Autopsy of 40 COVID-19 patients revealed that two thirds of the cases had disordered liver function tests. In this study, fibrosis in two livers, abscess for one of the cases and different levels of inflammation, ischemia, and steatosis in others livers were reported

The most prevalent histologic findings were macrovesicular steatosis, moderate acute hepatitis and minimal-to-mild portal inflammation. In the above mentioned study, $75 \%$ of the patients were reported to have liver steatosis, which was macrovesicular in all cases. It is required to mention that the majority of the patients in that study had diabetes. This can justify the high percentage of patients with liver steatosis reported in the study.

Liver enzyme disorders like variations in SGOT, SGPT and ALKP were observed as shown in table 2. In another study, 50\% of liver autopsy were reported to be steatotic (19).

It seems that regardless of underlying diseases like diabetes or drinking, COVID-19 infection causes steatosis in some patients. There are probably several contributing factors such as prescribing corticosteroids, hypoxia, malnutrition, and direct invasive impacts of the virus.

A study conducted in China showed the association between steatosis and the neutrophil to lymphocyte ratio (NLR ratio). The investigations showed that higher NLR is associated to more severe systemic inflammation. Thus, understanding the main mechanism of steatosis in Covid-19 requires further studies. findings of this study demonstrated that AST, ALT enzyme rising, revealed no statistically significant difference between patients with acute hepatitis and patients without lobular necroinflammation (20).

In the Stephen M et al. study (21), it was indicated that positive PCR test was significantly associated to acute hepatitis comparing to cases with negative PCR test results. The percentage of patients with acute hepatitis was $64 \%$ and $44 \%$ in positive PCR test group and negative PCR test group, respectively.

Bile duct injury was not observed in the present study like other related studies despite of the presence of ACE2 receptors (22) but cholestasis occurs commonly. Presence of lobular cholestasis without damaging biliary ducts is beneficial for hepatocellular injuries.

Endothelial injuries like lymphocytes endothelial inflammation and injury caused by COVID-19 have been reported in several studies (11, 22). In the present study vascular injury was not detected 
A case series study conducted in Italy investigated vascular pathology (23). However, there were no evidences supporting vast vascular liver injuries in our study like Stephen M. et.al study (21).

\section{Conclusions}

Our study shows extra-pulmonary multi organ involvement through COVID-19 disease. 77\% of patients representing acute or chronic hepatitis and $48 \%$ of them revealed lymphocytic myocarditis accompanied with pericarditis in $12 \%$ of cases and $12 \%$ of patient's show myositis. It looks diffuse inflammatory disease which attacks to some organs like myocardium, liver and muscles. Broad extra pulmonary pathology and laboratory findings are occurred that all suggestive of multi organ involvement directly or through systemic viremia and immune system response.

\section{Declarations}

\section{Ethics approval and consent to participate}

The Ethics Committee of Kurdistan University of Medical Sciences (IR.MUK. REC.1399.024) reviewed and approved this study. All patients provided written informed consents. The relevant guidelines and regulations performed all methods.

\section{Consent for publication}

Not applicable

\section{Availability of data and materials}

The datasets used and analyzed during the current study are available from the corresponding author on reasonable request.

\section{Competing interests}

The authors declare that they have no competing interests.

\section{Funding}

Vice-Chancellor funded this study for Research and Technology of Kurdistan University of Medical Sciences, Sanandaj, Iran.

\section{Authors' contributions}

$\mathrm{BM}, \mathrm{BN}$, and $\mathrm{KN}$ conceived and designed the study. BN, BM, KN and MAR analyzed and interpreted the data and drafted the manuscript. $\mathrm{BM}, \mathrm{BN}$, and $\mathrm{KN}$ were involved in the composition of the study tool, collect data, supervision of the research process, and critical revision and review of the manuscript. All the authors read and approved the final manuscript.

\section{Acknowledgment}

The authors would like to thank the Clinical Research Development Unit, Kowsar and Tohid Hospital of Kurdistan University of Medical Sciences.

\section{References}

1. Bradley BT, Maioli H, Johnston R, Chaudhry I, Fink SL, Xu H, et al. Histopathology and ultrastructural findings of fatal COVID-19 infections in Washington State: a case series. The Lancet. 2020;396(10247):320-32.

2. Sessa F, Bertozzi G, Cipolloni L, Baldari B, Cantatore S, D’errico S, et al. Clinical-forensic autopsy findings to defeat COVID-19 disease: a literature review. Journal of Clinical Medicine. 2020;9(7):2026.

3. D’Errico S, Zanon M, Montanaro M, Radaelli D, Sessa F, Di Mizio G, et al. More than pneumonia: distinctive features of SARS-CoV-2 infection. From autopsy findings to clinical implications: a systematic review. Microorganisms. 2020;8(11):1642.

4. Edler C, Schröder AS, Aepfelbacher M, Fitzek A, Heinemann A, Heinrich F, et al. Dying with SARS-CoV-2 infection-an autopsy study of the first consecutive 80 cases in Hamburg, Germany. International journal of legal medicine. 2020;134(4):1275-84. 
5. Fineschi V, Aprile A, Aquila I, Arcangeli M, Asmundo A, Bacci M, et al. Management of the corpse with suspect, probable or confirmed COVID-19 respiratory infection-Italian interim recommendations for personnel potentially exposed to material from corpses, including body fluids, in morgue structures and during autopsy practice. 2020.

6. Keten D, Okdemir E, Keten A. Precautions in postmortem examinations in Covid-19-Related deaths: Recommendations from Germany. Journal of Forensic and Legal Medicine. 2020;73:102000.

7. Remmelink M, De Mendonça R, D’Haene N, De Clercq S, Verocq C, Lebrun L, et al. Unspecific post-mortem findings despite multiorgan viral spread in COVID-19 patients. Critical care. 2020;24(1):1-10.

8. Barton LM, Duval EJ, Stroberg E, Ghosh S, Mukhopadhyay S. Covid-19 autopsies, oklahoma, usa. American journal of clinical pathology. 2020;153(6):725-33.

9. Magro C, Mulvey JJ, Berlin D, Nuovo G, Salvatore S, Harp J, et al. Complement associated microvascular injury and thrombosis in the pathogenesis of severe COVID-19 infection: a report of five cases. Translational Research. 2020;220:1-13.

10. Gattinoni L, Chiumello D, Caironi P, Busana M, Romitti F, Brazzi L, et al. COVID-19 pneumonia: different respiratory treatments for different phenotypes? : Springer; 2020.

11. Varga Z, Flammer AJ, Steiger P, Haberecker M, Andermatt R, Zinkernagel AS, et al. Endothelial cell infection and endotheliitis in COVID19. The Lancet. 2020;395(10234):1417-8.

12. Goldsmith CS, Miller SE, Martines RB, Bullock HA, Zaki SR. Electron microscopy of SARS-CoV-2: a challenging task. The Lancet. 2020;395(10238):e99.

13. Tian S, Xiong Y, Liu H, Niu L, Guo J, Liao M, et al. Pathological study of the 2019 novel coronavirus disease (COVID-19) through postmortem core biopsies. Modern Pathology. 2020;33(6):1007-14.

14. Ling Y, Xu S-B, Lin Y-X, Tian D, Zhu Z-Q, Dai F-H, et al. Persistence and clearance of viral RNA in 2019 novel coronavirus disease rehabilitation patients. Chinese medical journal. 2020;133(9):1039.

15. Xing Y-H, Ni W, Wu Q, Li W-J, Li G-J, Wang W-D, et al. Prolonged viral shedding in feces of pediatric patients with coronavirus disease 2019. Journal of microbiology, immunology and infection. 2020;53(3):473-80.

16. Heinz N, Griesemer A, Kinney J, Vittorio J, Lagana SM, Goldner D, et al. A case of an infant with SARS-CoV-2 hepatitis early after liver transplantation. Pediatric Transplantation. 2020;24(8):e13778.

17. Lagana SM, De Michele S, Lee MJ, Emond JC, Griesemer AD, Tulin-Silver SA, et al. COVID-19-associated hepatitis complicating recent living donor liver transplantation. Archives of pathology \& laboratory medicine. 2020;144(8):929-32.

18. Portincasa P, Krawczyk M, Machill A, Lammert F, Di Ciaula A. Hepatic consequences of COVID-19 infection. Lapping or biting? European journal of internal medicine. 2020;77:18-24.

19. Martines RB, Ritter JM, Matkovic E, Gary J, Bollweg BC, Bullock H, et al. Pathology and pathogenesis of SARS-CoV-2 associated with fatal coronavirus disease, United States. Emerging infectious diseases. 2020;26(9):2005.

20. Targher G, Mantovani A, Byrne C, Wang X-B, Yan H-D, Sun Q-F, et al. Detrimental effects of metabolic dysfunction-associated fatty liver disease and increased neutrophil-to-lymphocyte ratio on severity of COVID-19. Diabetes \& metabolism. 2020;46(6):505.

21. Lagana SM, Kudose S, luga AC, Lee MJ, Fazlollahi L, Remotti HE, et al. Hepatic pathology in patients dying of COVID-19: a series of 40 cases including clinical, histologic, and virologic data. Modern Pathology. 2020;33(11):2147-55.

22. Hamming I, Timens W, Bulthuis M, Lely A, Navis Gv, van Goor H. Tissue distribution of ACE2 protein, the functional receptor for SARS coronavirus. A first step in understanding SARS pathogenesis. The Journal of Pathology: A Journal of the Pathological Society of Great Britain and Ireland. 2004;203(2):631-7.

23. Sonzogni A, Previtali G, Seghezzi M, Grazia Alessio M, Gianatti A, Licini L, et al. Liver histopathology in severe CoVID 19 respiratory failure is suggestive of vascular alterations. Liver International. 2020;40(9):2110-6. 
Tables

Table 1. Patient characteristics, comorbidities and select initial laboratory findings

\begin{tabular}{|c|c|c|c|c|c|c|c|c|c|c|c|}
\hline Age & Sex & Comorbidity & Hospitalization(Day) & $\begin{array}{c}\text { Hospitalization } \\
\text { in ICU ward }\end{array}$ & $\begin{array}{l}\text { Hospitalization } \\
\text { in ward }\end{array}$ & Intubation & $\mathrm{Cr}$ & LDH & Anticoagulation & BUN & ESR \\
\hline 77 & Male & $\begin{array}{c}\text { Diabetes/ } \\
\text { CVA }\end{array}$ & 1 & 1 & 0 & Yes & 3 & 353 & positive & - & \\
\hline 84 & Male & BPH & 5 & 5 & & Yes & 3 & 7158 & positive & - & 16 \\
\hline 80 & Male & CVA & 12 & 6 & 6 & Yes & 1 & 1011 & positive & - & \\
\hline 59 & Male & - & 1 & & & Yes & & - & negative & - & \\
\hline 72 & Female & - & 5 & 3 & 2 & No & 2 & 22 & positive & - & \\
\hline 65 & Male & - & 5 & 4 & 1 & Yes & 1 & 988 & positive & - & \\
\hline 85 & Female & COPD & 8 & 7 & 1 & Yes & 1 & 949 & negative & 45 & 13 \\
\hline 52 & Female & Hypertension & 24 & 8 & 16 & Yes & 7 & 575 & negative & 74 & \\
\hline 80 & Male & - & 8 & 0 & 8 & No & 1 & 630 & positive & 45 & 50 \\
\hline 78 & Male & Hypertension & 13 & 4 & 9 & Yes & 1 & 1037 & positive & 29 & 50 \\
\hline 85 & Male & Cirrhosis & 2 & 0 & 2 & Yes & 3 & - & negative & 72 & \\
\hline 67 & Male & CVA & 11 & 8 & 3 & Yes & 5 & 336 & positive & 81 & 52 \\
\hline 76 & Male & - & 7 & 2 & 5 & Yes & 1 & 746 & negative & 37 & 5 \\
\hline 86 & Female & $\begin{array}{c}\text { Hypertension/ } \\
\text { CKD }\end{array}$ & 4 & 0 & 4 & Yes & 7 & 674 & positive & 67 & 40 \\
\hline 91 & Male & - & 6 & 5 & 1 & No & 1 & 1274 & positive & 18 & 15 \\
\hline 78 & Male & MI & 1 & 0 & 1 & No & 1 & 927 & positive & 17 & \\
\hline 80 & Male & Hypertension & 4 & 0 & 4 & Yes & 2 & 1649 & positive & 3 & 30 \\
\hline 70 & Male & Hypertension & 54 & 35 & 19 & Yes & 1 & & positive & 7 & 38 \\
\hline 79 & Male & $\begin{array}{c}\text { Diabetes/ } \\
\text { Prostate } \\
\text { Cancer }\end{array}$ & 10 & 2 & 8 & Yes & 1 & 435 & negative & 3 & 1649 \\
\hline 71 & Female & Single kidney & 28 & 28 & - & Yes & 2 & 564 & negative & 58 & \\
\hline 68 & Male & Diabetes & 2 & 0 & 2 & Yes & 3 & - & positive & 60 & \\
\hline 64 & Male & $\begin{array}{c}\text { RA/COPD/ } \\
\text { Hypertension }\end{array}$ & 1 & 1 & 0 & No & & - & positive & - & \\
\hline 70 & Male & MI & 1 & & & Yes & & - & negative & - & \\
\hline 66 & Male & Hypertension & 1 & 0 & 0 & Yes & 3 & 353 & positive & - & \\
\hline 84 & Female & - & 8 & 7 & 1 & No & 3 & 7158 & positive & 27 & 16 \\
\hline
\end{tabular}

Table 2. Summary of laboratory result

\begin{tabular}{|c|c|c|}
\hline ariable & Mean \pm SD (Min-Max) & Normal Range \\
\hline $\mathrm{r}, \mathrm{N}=20$ & $2.29 \pm 1.89(1-7)$ & Male: $0.8-1.3$, Female: $0.6-1.2$ \\
\hline $\mathrm{UN}, \mathrm{N}=16$ & $40.16 \pm 26.49(3-81)$ & $6-20 \mathrm{mg} / \mathrm{dl}$ \\
\hline $\mathrm{SR}, \mathrm{N}=11$ & $178 \pm 488(5-1649)$ & Male:5 - 12, Female: 6-20 \\
\hline$\overline{\mathrm{DH}}, \mathrm{N}=17$ & $1136 \pm 1599(22-7158)$ & $235-470$ \\
\hline $\mathrm{PK}, \mathrm{N}=12$ & $919 \pm 1429(61-4984)$ & Male: $0-171$, Female: $0-145$ \\
\hline -dimer, $\mathrm{N}=8$ & $365 \pm 741(1-2188)$ & $<200$ \\
\hline erritin, $\mathrm{N}=9$ & $1206 \pm 941(8.5-2375)$ & Male: 21.8- 276, Female:4.63-204 \\
\hline $\mathrm{a}, \mathrm{N}=13$ & $8.41 \pm 0.46(7.5-9.1)$ & $8.6-10.3$ \\
\hline $\mathrm{g}, \mathrm{N}=12$ & $2.46 \pm 0.76(1.7-7.5)$ & $1.53-2.55$ \\
\hline GOT, $N=15$ & $65.6 \pm 53.4(14-180)$ & Male: $<40$, Female: $<40$ \\
\hline GPT, $N=15$ & $253.9 \pm 808.6(10-3170)$ & Male: $<45$, Female: $<34$ \\
\hline $\mathrm{LKP}$ & $225 \pm 88.1(119-373)$ & Male: $0-270$, Female: $0-240$ \\
\hline
\end{tabular}

Table 3. Frequency of patient's comorbidities 


\begin{tabular}{|l|c|c|}
\hline omorbidity & $\mathrm{N}=25$ & Percent \\
\hline ypertension & 7 & 28 \\
\hline$\overline{\text { II }}$ & 2 & 8 \\
\hline VA & 3 & 12 \\
\hline iabetes & 3 & 12 \\
\hline irrhosis & 1 & 4 \\
\hline KD & 1 & 4 \\
\hline ingle kidney & 1 & 4 \\
\hline OPD & 2 & 8 \\
\hline rostate Cancer & 1 & 4 \\
\hline enign prostatic hyperplasia (BPH) & 1 & 4 \\
\hline o Comorbidity & 7 & 28 \\
\hline
\end{tabular}

Table 4. Post-mortem findings by organ system by patient 
ase Heart

Unremarkable cardiac tissue

Skin tissue

Iron stain negative

The smooth muscle (seems to have been sampled from the large artery)

Mild viral myocarditis

Adipose tissue (Pericardium)

Unremarkable skin tissue

Iron stain: negative

Unremarkable iron stain: negative

Mild lymphosytis miocarditis

Miocarditis

Iron stain: negative

Unremarkable

Iron stain: negative

Unremarkable

Iron stain: negative

o Connective tissue, fat, striated muscle, cartilage tissues (Non cardiac tissue)

Iron stain: negative

$1 \quad$ Unremarkable

Mild lymphocytis myocarditis

Iron stain: negative

$2 \quad$ Mild lymphocytis

Myocarditis with focal interstitial

fibrosis

Iron stain: negative

3

Mild

Myocarditis

Pricarditis

Iron stain: negative

$4 \quad$ Connective tissue, fat and skin tissue

\begin{tabular}{l|l}
\hline & \\
\hline $\mathbf{5}$ & Connective tissue, fat and skin tissue \\
\hline & \\
\hline $\mathbf{6}$ & $\begin{array}{l}\text { Connective tissue, fat, cartilage tissues } \\
\text { (Non cardiac tissue) }\end{array}$ \\
\hline & \multicolumn{1}{|c}{} \\
\hline $\mathbf{7}$ & Stomach tissue \\
\hline & \\
\hline $\mathbf{B}$ & Mild lymphocytis \\
\hline & Miocarditis \\
\hline & \multicolumn{2}{|c|}{}
\end{tabular}

Liver

Unremarkable

Trichrome stain: Mild

periportal fibrosis

Iron stain: negative

Chronic acute hepatitis

grade1/6

Trichrome stain: fibrosis

stage $1 / 6$

Iron stain: negative

Skin tissue

$-$

Muscle tissue

Macrovesicular

steatostist

Hepatitis(Steatohepatitis)

Trichrom stain: negative

Iron stain: negative

Unremarkable

Trichrome stain: negative

Iron stain: negative

Unremarkable liver

tissue

Trichrome stain: normal

Iron stain: normal

Unremarkable

Unremarkable

Trichrome stain: negative

Iron stain: negative

Cirrhosis (Incomplete)

Fibrosis stage: 5

Trichrome stain:

incomplete cirrhosis

Chronic active hepatitis

Fibrosis stage: 2

Iron stain: negative

Chronic Cirrhosis

Hepatitis (mild form)

Trichrome stain: negative

Iron stain: negative

Chronic active hepatitis

(grade 1/6)

Trichrome stain: negative

Iron stain: negative

Chronic active hepatitis

(grade 1/6)

Trichrome stain: fibrosis

stage 2

Iron stain: normal

Mild acute hepatitis

Trichrome stain: negative

Iron stain: normal

Mild acute hepatitis

Trichrome stain: negative

Iron stain: negative

Acute hepatitis

Trichrome stain: negative
Muscle

Testis

Unremarkable

Unremarkable

Mild

lymphocytic

(Viral) myositis

myositis

Mild viral $\quad$ Sertolicell only

myositis

syndrome (germinal

cell aplsia)

Skin tissue

Unremarkable

Unremarkable

Unremarkable

\section{U}

Unremarkable

Unremarkable

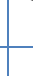

-

Unr

Unremarkable

Un

Unremarkable

Unremarkable

Unremarkable

Unremarkable

Unremarkable

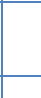

Unr

\begin{tabular}{|l|l} 
Unremarkable & Connective tissue \\
\hline &
\end{tabular}

Unremarkable

Unremarkable $\quad$ Unremarkable

Unr

Un

Unremarkable

Unremarkable+ Unremarkable

Skin tissue

Page 10/11 


\begin{tabular}{|c|c|c|c|c|}
\hline \multirow{4}{*}{9} & Iron stain: negative & Iron stain: negative & & \\
\hline & Mild lymphocytis & Steato hepatitis & & \\
\hline & Miocarditis & $\begin{array}{l}\text { Trichrome stain: fibrosis } \\
\text { stage } 1\end{array}$ & Unremarkable & - \\
\hline & Iron stain: negative & Iron stain: negative & & \\
\hline \multirow[t]{4}{*}{$\overline{0}$} & Miocarditis & Mild acute hepatitis & & Unremarkable \\
\hline & Pricarditis & Trichrome stain: negative & & \\
\hline & lymphocytis & Iron stain: negative & & \\
\hline & Viral miocarditis & & & \\
\hline \multirow[t]{4}{*}{1} & Mild miocarditis & Macrovesicular steatosis & Unremarkable & Unremarkable \\
\hline & Precarditis & $\begin{array}{l}\text { Hepatitis (Steato- } \\
\text { hepatitis) }\end{array}$ & & \\
\hline & Iron stain: negative & $\begin{array}{l}\text { Fibrosis stage } 4 \\
\text { (Trichrome stain) }\end{array}$ & & \\
\hline & & Iron stain: negative & & \\
\hline \multirow[t]{3}{*}{2} & Mild lymphocytic & Steato-hepatitis & Unremarkable & Unremarkable \\
\hline & Miocarditis & Trichrome stain: negative & & \\
\hline & Iron stain: negative & Iron stain: negative & & \\
\hline \multirow[t]{4}{*}{3} & Unremarkable & Mcrovascular stratosis & Unremarkable & Unremarkable \\
\hline & Iron stain: negative & $\begin{array}{l}\text { Hepatitis (Steato- } \\
\text { hepatitis) }\end{array}$ & & \\
\hline & & $\begin{array}{l}\text { Trichrome stain: mild } \\
\text { periportal fibrosis(stage } \\
\text { 1) }\end{array}$ & & \\
\hline & & Iron stain: normal & & \\
\hline \multirow[t]{4}{*}{4} & Fatty replacement & Steatohepatitis & Unremarkable & Unremarkable \\
\hline & Mild lymphocytis & Trichrome stain: negative & & \\
\hline & Miocarditis & & & \\
\hline & Iron stain: negative & & & \\
\hline \multirow[t]{2}{*}{5} & Mild miocarditis & Mild lobular & $\begin{array}{l}\text { Mild viral } \\
\text { myositis }\end{array}$ & - \\
\hline & & Portal hepatitis & & \\
\hline
\end{tabular}

\section{Figures}

\section{Figure 1}

Mild lymphocytic myocarditis

屈

\section{Figure 2}

Heart, fatty replacement

\section{Figure 3}

Steatohepatitis (Medium power)

左

\section{Figure 4}

Cirrhosis 